OPEN ACCESS

Edited by:

Diogo C. Haussen

Emory University, United States

Reviewed by:

Alberto Maud,

Texas Tech University Health Sciences

Center El Paso, United States

Waldo Rigoberto Guerrero,

University of South Florida,

United States

*Correspondence:

Yisen Zhang

zhang-yisen@163.com

Ming LV

dragontiger@163.com

Specialty section:

This article was submitted to Endovascular and Interventional

Neurology

a section of the journal

Frontiers in Neurology

Received: 10 February 2021 Accepted: 07 April 2021

Published: 29 April 2021

Citation:

Zhang L, Chen X, Dong L, Liu P, Jia L, Zhang $Y$ and LV M (2021) Clinical and

Angiographic Outcomes After

Stent-Assisted Coiling of Cerebral Aneurysms With Laser-Cut and

Braided Stents: A Comparative

Analysis of the Literatures.

Front. Neurol. 12:666481.

doi: 10.3389/fneur.2021.666481

\section{Clinical and Angiographic Outcomes After Stent-Assisted Coiling of Cerebral Aneurysms With Laser-Cut and Braided Stents: A Comparative Analysis of the Literatures}

\author{
Longhui Zhang, Xiheng Chen, Linggen Dong, Peng Liu, Luqiong Jia, Yisen Zhang* and \\ Ming $L v^{*}$
}

Department of Interventional Neuroradiology, Beijing Neurosurgical Institute, Beijing Tian Tan Hospital, Capital Medical University, Beijing, China

Introduction: Stent-assisted coiling (SAC) plays an important role in endovascular treatment of intracranial aneurysms (IAs). This comparative analysis examines the safety and efficacy of SAC in general and compares clinical and angiographic outcomes between laser-cut stents and braided stents.

Methods: Relevant English-language studies were identified via a PubMed search for published articles regarding outcomes of SAC using laser-cut stents and braided stents published from 2015 to 2020. Data from 56 studies that met our inclusion criteria were pooled and statistically compared.

Results: A total of 4,373 patients harboring with 4,540 IAs were included. Patients were divided into two groups on the basis of stent type: laser-cut stents $(2,076$ aneurysms in 1991 patients; mean follow-up, 12.99 months) and braided stents (2,464 aneurysms in 2382 patients; mean follow-up, 18.41 months). Overall, the rates of successful stent deployment, thromboembolic events, stent stenosis, periprocedural intracranial hemorrhage, permanent morbidity, mortality, and recanalization were 97.72, 4.72, 2.87, $1.51,2.14,1.16$, and $6.06 \%$, respectively. Laser-cut stents were associated with a significantly higher rate of successful deployment $(p=0.003)$ and significantly lower rate of periprocedural intracranial hemorrhage $(p=0.048)$. Braided stents were associated with a significantly lower rate of permanent morbidity $(p=0.015)$.

Conclusion: SAC of IAs using laser-cut stents or braided stents was effective and safe. Rates of thromboembolic events, stent stenosis, mortality, and recanalization were comparable between the stent types. Braided stents were associated with lower permanent morbidity while laser-cut stents were associated with more favorable rates of successful deployment and periprocedural intracranial hemorrhage.

Keywords: intracranial aneurysm, endovascular treatment, stent-assisted coiling, the laser-cut stent, the braided stent 


\section{INTRODUCTION}

Surgical clipping and endovascular therapy are the two main treatment options for patients with intracranial aneurysms (IAs). Detection of IAs is increasing because of widespread use of non-invasive intracranial vascular examination techniques such as magnetic resonance angiography. Since the use of Guglielmi detachable coils (GDC) for endovascular IA treatment was introduced in the 1990s (1), the advent of various types of coils and stents has ushered in a Golden Age of endovascular treatment, with stent-assisted coiling (SAC) playing an important role over the past decade.

Patients have widely accepted SAC because of good clinical outcomes $(2,3)$. In this technique, stent deployment serves as a scaffold to prevent coil prolapse, which preserves the parent artery and promotes thrombosis in the aneurysm and re-endothelialization, resulting in improved outcome (4). Lasercut and braided stents are the primary intracranial stents in use today. Laser-cut stents are characterized by high vascular compliance, good flexibility, excellent stability, and fewer thromboembolic events in collateral vessels; examples include Neuroform (Stryker Neurovascular, Kalamazoo, MI, USA), Neuroform Atlas (Stryker Neurovascular), Enterprise (Codman Neuro, Raynham, MA, USA), and Solitaire (Medtronic, Dublin, Ireland). Self-expanding braided stents have greater metal surface coverage and provide greater flow diversion to promote aneurysmal occlusion; examples include LVIS (Microvention, Aliso Viejo, CA, USA), LVIS Jr (Microvention), and LEO Baby (Balt, Montmorency, France). Both stent types are widely used in IA management and type superiority has not been established $(5,6)$.

SAC studies have been increasing owing to a 2013 review of intracranial stenting (7), increased stenting experience, improvements in stenting technology, and increased IA detection; however, results have been variable. Therefore, an up-to-date review of this rapidly developing field is needed. This study aimed to review recent relevant literature to compare clinical and angiographic outcomes of SAC with laser-cut and braided stents and to comment on the safety and efficacy of SAC in general.

\section{METHODS}

\section{Data Sources}

The PubMed database was searched for relevant articles published from January 2015 to October 2020 regarding Neuroform, Neuroform Atlas, Enterprise, Solitaire, LVIS, LVIS Jr, and LEO Baby stents. Search terms included "[stent name]," "[stent name] + stent," and "[stent name] + intracranial aneurysm." Studies which met the following criteria were reviewed: (a) abstract and/or entire manuscript was published in English; (b) case series, prospective study, or clinical trial that included nine or more patients; (c) detailed clinical and/or radiological post-intracranial stenting data were reported; (d) multiple stent systems were studied with individual system data clearly reported. In cases of controversy, the entire article was thoroughly reviewed. Patients who received more than one type of stent were excluded.

\section{Data Extraction}

The following data from articles meeting our inclusion criteria were reviewed and extracted: sample size, deployment success, thromboembolic events, periprocedural intracranial hemorrhage, stent stenosis, permanent morbidity (present at last follow-up), mortality, angiographic aneurysmal occlusion immediately following the procedure and at last follow-up, and recanalization. Thromboembolic events were defined as stroke, transient ischemic attack, or development of asymptomatic thrombus during the procedure. Stent stenosis was defined as "moderate," "severe," or "symptomatic" stenosis, or as $\geq 50 \%$ stenosis if quantified (8-10). Angiographic occlusion was defined in accordance with the Raymond-Roy classification and the modified Raymond-Roy classification (11, 12). Recanalization was defined as "recanalization" or "recurrence"; residual aneurysms that increased in size and aneurysms that progressed to a higher Raymond-Roy class were also considered recanalized. All data were reviewed and verified independently by the two authors and entered into the study database using specialized forms. In some outcome analyses, patients from studies with missing data were excluded from the analysis.

\section{Statistical Analysis}

Statistical analyses were performed using SPSS software version 26 (IBM Corp., Armonk, NY, USA.). Continuous data are presented as means. Categorical data are presented as frequencies or percentages and were compared using the two-tailed Fischer exact test. $P<0.05$ was considered significant.

\section{RESULTS}

A total of 56 studies comprising 4,373 patients harboring 4,540 aneurysms were included $(6,13-67)$. Patients were divided into two groups on the basis of stent type: laser-cut stents $(2,076$ aneurysms in 1991 patients; mean follow-up, 12.99 months) and braided stents (2,464 aneurysms in 2,382 patients; mean follow-up, 18.41 months). Both stents performed equally well, with no significant difference in frequencies of thromboembolic events, stent stenosis events, mortality, recanalization, and class 1 (complete) and class 2 (near-complete) Raymond-Roy angiographic occlusion between groups. Frequency of successful deployment was significantly higher in the laser-cut stent group ( 98.69 vs. $97.07 \%, p=0.003$ ), while frequency of periprocedural intracranial hemorrhage was significantly lower (1.13 vs. $1.85 \%$, $p=0.048$ ). Frequency of permanent morbidity was significantly lower in the braided stent group ( 1.58 vs. $2.92 \%, p=0.015$ ). Rates of clinical complications and class 1 and class 2 angiographic occlusion overall and according to stent type are presented in Table 1. Denominators of the analyses vary based on the number of patients with available data.

\section{DISCUSSION}

Our comparative analysis of 4,540 aneurysms in 4,373 patients found that SAC of IAs using either laser-cut or braided stents had favorable clinical outcomes and angiographic results. Overall, rates of mortality, permanent morbidity, and recanalization were low, suggesting that SAC is safe and effective. 
TABLE 1 | The clinical and angiographic outcomes after stent-assisted coiling of cerebral aneurysms with laser-cut and braided stents.

\begin{tabular}{|c|c|c|c|c|}
\hline & Total $N(\%)$ & Laser engraving stent $N(\%)$ & Braided stents $N(\%)$ & $p$-value \\
\hline Number of patients & 4,373 & 1,991 & 2,382 & $\mathrm{~N} / \mathrm{A}$ \\
\hline Number of aneurysms & 4,540 & 2,076 & 2,464 & $\mathrm{~N} / \mathrm{A}$ \\
\hline Deployment success, \% & 2957/3026 (97.72) & 1202/1218 (98.69) & 1755/1808 (97.07) & 0.003 \\
\hline Thromboembolic events & $210 / 4451(4.72)$ & 90/2077 (4.33) & 120/2374 (5.05) & 0.288 \\
\hline In-stent stenosis & 83/2887 (2.87) & $32 / 1089$ (2.94) & $51 / 1798(2.84)$ & 0.909 \\
\hline Initial Raymond 2 & 1009/4293 (23.50) & $441 / 1909(23.10)$ & 568/2384 (23.82) & 0.587 \\
\hline Initial Raymond 3 & 598/4293 (13.93) & 260/1909 (13.61) & 338/2384 (14.18) & 0.626 \\
\hline Last follow-up Raymond 1 & 2453/3109 (78.90) & $1175 / 1478(79.50)$ & 1278/1631 (78.36) & 0.454 \\
\hline Last follow-up Raymond 2 & 401/3109 (12.90) & $175 / 1478(11.84)$ & 226/1631 (13.86) & 0.097 \\
\hline Last follow-up Raymond 3 & 255/3109 (8.20) & $128 / 1478(8.66)$ & $127 / 1631(7.79)$ & 0.395 \\
\hline
\end{tabular}

Laser-cut stents: Enterprise, Neuroform, Neuroform atlas, Solitaire.

Braided Stents: Lvis, Lvis Jr, Leo baby.

Early endovascular coiling studies indicated that low coil density, large aneurysm size, and wide aneurysm neck are recanalization risk factors (68). However, the development of SAC has enabled treatment of wide-neck, complex, and bifurcation intracranial aneurysms. Stent deployment significantly improves outcome by serving as a scaffold to prevent coil prolapse and preserve the parent artery. This promotes thrombosis in the aneurysm lumen as well as reendothelialization and may explain why SAC has a lower recanalization rate than coil embolization alone. However, stent placement is associated with higher procedural risk and risk of stent thrombosis.

Braided stents in our study were represented by LVIS, LVIS Jr, and LEO Baby. These stents have greater metal surface coverage and provide greater flow diversion, which promotes IA occlusion and results in fewer adverse ischemic events. Laser-cut stents were represented by the Neuroform, Enterprise, and Solitaire series of stents. These stents have the advantages of high vascular compliance, good flexibility, excellent stability, and fewer thromboembolic events in collateral vessels. Our comparative analysis resulted in several significant findings. The rates of successful deployment and periprocedural intracranial hemorrhage favored laser-cut stents; however, permanent morbidity was significantly lower in patients who underwent SAC with braided stents. In addition, rates of angiographic aneurysmal occlusion, thromboembolic events, stent stenosis, mortality, and recanalization did not differ between the two groups. However, several different individual stents were used in each group and the data are representative of multiple device iterations, different operators, and accumulated institutional experience over the past 6 years. Our findings may not be applicable to current practice and should be interpreted with caution.
To be noted, previous studies demonstrated that braided stents have greater metal surface coverage and provide greater flow diversion, which promotes IA occlusion. Feng et al. showed that LVIS stents may achieve lower rate of recanalization and instent stenosis than Enterprise (38). Ge et al. reported a higher rate of recanalization associated with enterprise stent than with the LVIS stent (10.7 vs $2.8 \%$ ) (25). Lim et al. observed in SAC of IAs, laser- cut and braided stent groups produced similar outcomes in follow-up, the difference of recanalization incidence rates between the braided- stent and the laser-cut group was not statistically significant (5).

Unlike previous studies, there are more than one kind of stent in both two groups. Our study finding is similar to that of many previous studies, the recurrence rate of laser-cut stents is higher than braided stents (91/1325 6.87\% vs 109/1973 5.52\%). Overall, the result was encouraging, with minor difference.

The present studies containing 4,373 aneurysms in more than 4,500 patients in recent 6 years. It is an up-to-date and robust review of this rapidly developing field. This comparative analysis demonstrated that both laser-cut stents and braided stents had good clinical outcomes. Overall, high rate of deployment success $(97.72 \%)$, initial and final completely and near completely angiographic occlusion was seen in 86.07 and $91.80 \%$ of patients, low rate of thromboembolic events (4.72\%) and Instent stenosis (2.87\%), low permanent morbidity $(2.14 \%)$, and mortality $(1.16 \%)$.

The low clinical complication rate, high deployment success and high degree of occlusion are particularly encouraging, which may result from the increased stenting experience, improvements in stenting technology, and increased IA detection.

The advantages of laser-cut stents characterized by high vascular compliance, good flexibility, excellent stability (24). Besides, the push technique and the release of braided stents 
as well as catheter pullback are difficult, especially in tortuous vessels. The above mentioned could account for more favorable deployment and less peri-procedural intracranial hemorrhage in laser-cut stents group.

In this study, we made a comparative analysis between the published results of the laser-cut stents and braided stents demonstrated that both laser- cut and braided stent groups produced similar outcomes in SAC of IAs. The pooled data include studies across multiple device iterations in the recent 6 years, the data do not necessarily represent the procedural device failures, clinical complications, or occlusion of the most modern device iterations or procedural techniques used currently. These results should be interpreted with caution.

This study has significant limitations. First, numerous retrospective studies were analyzed, each with their own biases. Second, heterogeneity between the analyzed studies may weaken the generalizability and validity of our findings. Third, the study data were pooled from previously published studies without stringent inclusion criteria, and the scientific quality of the included studies was not graded. Fourth, we did not consider IA location, number of stents used, stent length, stent cost and availability, and different follow-up durations and did not compare stent morphological characteristics between groups, which may have introduced significant bias. Furthermore, direct comparisons between studies were difficult as data reporting was

\section{REFERENCES}

1. Guglielmi G, Viñuela F, Duckwiler G, Dion J, Lylyk P, Berenstein A, et al. Endovascular treatment of posterior circulation aneurysms by electrothrombosis using electrically detachable coils. J Neurosurg. (1992) 77:515-24. doi: 10.3171/jns.1992.77.4.0515

2. Wiebers DO, Whisnant JP, Huston J 3rd, Meissner I, Brown RD Jr, et al. Torner JC. Unruptured intracranial aneurysms: natural history, clinical outcome, and risks of surgical and endovascular treatment. Lancet. (2003) 362:10310. doi: 10.1016/S0140-6736(03)13860-3

3. Molyneux AJ, Kerr RS, Yu LM, Clarke M, Sneade M, Yarnold JA, et al. International subarachnoid aneurysm trial (ISAT) of neurosurgical clipping versus endovascular coiling in 2143 patients with ruptured intracranial aneurysms: a randomised comparison of effects on survival, dependency, seizures, rebleeding, subgroups, aneurysm occlusion. Lancet. (2005) 366:80917. doi: 10.1016/S0140-6736(05)67214-5

4. Koebbe CJ, Veznedaroglu E, Jabbour P, Rosenwasser RH. Endovascular management of intracranial aneurysms: current experience and future advances. Neurosurgery. (2006) 59(5 Suppl. 3):S93-102; discussion S103113. doi: 10.1227/01.NEU.0000237512.10529.58

5. Lim J, Cho YD, Hong N, Lee J, Yoo DH, Kang HS. Follow-up outcomes of intracranial aneurysms treated using braided or laser-cut stents with closed-cell design: a propensity score-matched case-controlled comparison. J Neurointerv Surg. (2020) 13:434-7. doi: 10.1136/neurintsurg-2020-016165

6. Mokin M, Primiani CT, Ren Z, Piper K, Fiorella DJ, Rai AT, et al. Stentassisted coiling of cerebral aneurysms: multi-center analysis of radiographic and clinical outcomes in 659 patients. J Neurointerv Surg. (2020) 12:28997. doi: 10.1136/neurintsurg-2019-015182

7. Gross BA, Frerichs KU. Stent usage in the treatment of intracranial aneurysms: past, present and future. J Neurol Neurosurg Psychiatry. (2013) 84:24453. doi: 10.1136/jnnp-2011-302007

8. Fiorella D, Albuquerque FC, Woo $\mathrm{H}$, Rasmussen PA, Masaryk TJ, McDougall CG. Neuroform in-stent stenosis: incidence, natural history, treatment strategies. Neurosurgery. (2006) 59:34-42; discussion 34-42. doi: 10.1227/01.NEU.0000219853.56553.71 variable. Finally, the reported $6.06 \%$ recanalization rate probably significantly underestimates the true rate (69).

\section{CONCLUSION}

This analysis of 4,373 patients harboring 4,540 IAs who underwent SAC with laser-cut or braided stents within the past 6 years found that SAC is safe and effective. Rates of permanent morbidity, mortality, and recanalization were comparable between the devices; however, braided stents were associated with lower permanent morbidity while laser-cut stents were associated with more favorable rates of successful deployment and periprocedural intracranial hemorrhage.

\section{AUTHOR CONTRIBUTIONS}

LZ drafted the manuscript and prepared the table. XC, PL, LD, and $\mathrm{LJ}$ conducted data collection. ML and YZ conceived and designed this project. All authors reviewed the manuscript.

\section{FUNDING}

This work was supported by the National Nature Science Foundation of China (Grant Number 81901197, 81801158), Beijing Hospitals Authority Youth Programme (QML20190503).
9. Mocco J, Fargen KM, Albuquerque FC, Bendok BR, Boulos AS, Carpenter JS, et al. Delayed thrombosis or stenosis following enterprise-assisted stent-coiling: is it safe? Midterm results of the interstate collaboration of enterprise stent coiling. Neurosurgery. (2011) 69:908-13; discussion 913904. doi: 10.1227/NEU.0b013e318228490c

10. King B, Vaziri S, Singla A, Fargen KM, Mocco J. Clinical and angiographic outcomes after stent-assisted coiling of cerebral aneurysms with Enterprise and Neuroform stents: a comparative analysis of the literature. J Neurointerv Surg. (2015) 7:905-9. doi: 10.1136/neurintsurg-2014-011457

11. Roy D, Milot G, Raymond J. Endovascular treatment of unruptured aneurysms. Stroke. (2001) 32:1998-2004. doi: 10.1161/hs0901.095600

12. Stapleton CJ, Torok CM, Rabinov JD, Walcott BP, Mascitelli JR, LeslieMazwi TM, et al. Validation of the Modified Raymond-Roy classification for intracranial aneurysms treated with coil embolization. J Neurointerv Surg. (2016) 8:927-33. doi: 10.1136/neurintsurg-2015-012035

13. Chung J, Suh SH, Hong CK, Joo JY, Lim YC, Shin YS, et al. Preliminary experience with self-expanding closed-cell stent placement in small arteries less than $2 \mathrm{~mm}$ in diameter for the treatment of intracranial aneurysms. $J$ Neurosurg. (2015) 122:1503-10. doi: 10.3171/2014.11.JNS14435

14. Cui YF, Xu H, Liu HT, Wang Y. Clinical application of solitaire AB stents in the embolization of intracranial aneurysms. Eur Rev Med Pharmacol Sci. (2015) 19:1227-33. Available online at: https://www.europeanreview.org/ article/8741

15. Feng Z, Li Q, Zhao R, Zhang $\mathrm{P}$, Chen $\mathrm{L}$, Xu $\mathrm{Y}$, et al. Endovascular Treatment of middle cerebral artery aneurysm with the LVIS junior stent. J Stroke Cerebrovasc Dis. (2015) 24:1357-62. doi: 10.1016/j.jstrokecerebrovasdis.2015.02.016

16. Feng Z, Zhang L, Li Q, Zhao R, Xu Y, Hong B, et al. Endovascular treatment of wide-neck anterior communicating artery aneurysms using the LVIS Junior stent. J Clin Neurosci. (2015) 22:1288-91. doi: 10.1016/j.jocn.2015. 02.020

17. Li TF, Shui SF, Han XW, Yan L, Ma J, Guo D, et al. The use of solitaire $\mathrm{AB}$ stents in coil embolization of wide-necked cerebral aneurysms. PLoS ONE. (2015) 10:e0139714. doi: 10.1371/journal.pone.013 9714 
18. Liu A, Peng T, Qian Z, Li Y, Jiang C, Wu Z, et al. Enterprise stent-assisted coiling for wide-necked intracranial aneurysms during ultra-early (48hours) subarachnoid hemorrhage: a single-center experience in 59 consecutive patients. J Neuroradiol. (2015) 42:298-303. doi: 10.1016/j.neurad.2014. 11.005

19. Poncyljusz W, Biliński P, Safranow K, Baron J, Zbroszczyk M, Jaworski $\mathrm{M}$, et al. The LVIS/LVIS Jr. stents in the treatment of wide-neck intracranial aneurysms: multicentre registry. J Neurointerv Surg. (2015) 7:5249. doi: 10.1136/neurintsurg-2014-011229

20. Yu M, Liu F, Jiang S, Nie B. Stent-assisted coiling for the treatment of ruptured micro-intracranial wide-necked aneurysms. Interv Neuroradiol. (2015) 21:403. doi: 10.1177/INR-2014-10097

21. Zhang J, Wang D, Li X. Solitaire AB stent-assisted coiling embolization for the treatment of ruptured very small intracranial aneurysms. Exp Ther Med. (2015) 10:2239-44. doi: 10.3892/etm.2015.2826

22. Alghamdi F, Mine B, Morais R, Scillia P, Lubicz B. Stent-assisted coiling of intracranial aneurysms located on small vessels: midterm results with the LVIS Junior stent in 40 patients with 43 aneurysms. Neuroradiology. (2016) 58:665-71. doi: 10.1007/s00234-016-1668-z

23. Du EHY, Shankar JJS. LVIS Jr 'shelf' technique: an alternative to Y stent-assisted aneurysm coiling. J Neurointerv Surg. (2016) 8:12569. doi: 10.1136/neurintsurg-2015-012246

24. Feng Z, Fang Y, Xu Y, Hong B, Zhao W, Liu J, et al. The safety and efficacy of low profile visualized intraluminal support (LVIS) stents in assisting coil embolization of intracranial saccular aneurysms: a single center experience. $J$ Neurointerv Surg. (2016) 8:1192-6. doi: 10.1136/neurintsurg-2015-012090

25. Ge H, Lv X, Yang X, He H, Jin H, Li Y. LVIS stent versus enterprise stent for the treatment of unruptured intracranial aneurysms. World Neurosurg. (2016) 91:365-70. doi: 10.1016/j.wneu.2016.04.057

26. Li XD, Qin J, Xiao ZY, Feng Y, Chen JK. Solitaire AB stent-assisted coiling of wide-neck micro aneurysms. J Korean Neurosurg Soc. (2016) 59:3415. doi: 10.3340/jkns.2016.59.4.341

27. Limbucci N, Renieri L, Nappini S, Consoli A, Rosi A, Mangiafico S. Y-stent assisted coiling of bifurcation aneurysms with enterprise stent: long-term follow-up. J Neurointerv Surg. (2016) 8:158-62. doi: 10.1136/neurintsurg-2014-011483

28. Samaniego EA, Abdo G, Hanel RA, Lima A, Ortega-Gutierrez S, Dabus G. Endovascular treatment of PICA aneurysms with a low-profile visualized intraluminal support (LVIS Jr) device. J Neurointerv Surg. (2016) 8:10303. doi: 10.1136/neurintsurg-2015-012070

29. Castaño C, Terceño M, Remollo S, García-Sort MR, Domínguez C. Endovascular treatment of wide-neck intracranial bifurcation aneurysms with 'Y'-configuration, double Neuroform $\AA$ stents-assisted coiling technique: experience in a single center. Interv Neuroradiol. (2017) 23:362-70. doi: 10.1177/1591019917708568

30. Chen Y, Zhang Y, Chao YJ, Gao G, Ni CS, Fu XM, et al. Stent-assisted coiling embolization of middle cerebral artery trifurcation wide-necked aneurysms. Eur Rev Med Pharmacol Sci. (2017) 21:4346-9. Available online at: https:// www.europeanreview.org/article/13505

31. Grossberg JA, Hanel RA, Dabus G, Keigher K, Haussen DC, Sauvageau E, et al. Treatment of wide-necked aneurysms with the Low-profile Visualized Intraluminal Support (LVIS Jr) device: a multicenter experience. J Neurointerv Surg. (2017) 9:1098-102. doi: 10.1136/neurintsurg-2016-012687

32. Lubicz B, Kadou A, Morais R, Mine B. Leo stent for endovascular treatment of intracranial aneurysms: very long-term results in 50 patients with 52 aneurysms and literature review. Neuroradiology. (2017) 59:2716. doi: 10.1007/s00234-017-1805-3

33. Qin F, Li Z, Fang X, Zhao X, Liu J, Wu D, et al. Therapeutic effect of enterprise stent-assisted embolization for very small ruptured intracranial aneurysms. Medicine (Baltimore). (2017) 96:e7832. doi: 10.1097/MD.0000000000007832

34. Shankar JJS, Quateen A, Weill A, Tampieri D, Del Pilar Cortes M, Fahed R, et al. Canadian Registry of LVIS Jr for Treatment of Intracranial Aneurysms (CaRLA). J Neurointerv Surg. (2017) 9:849-53. doi: 10.1136/neurintsurg-2016-012611

35. Voigt P, Schob S, Jantschke R, Nestler U, Krause M, Weise D, et al. Stent-assisted coiling of ruptured and incidental aneurysms of the intracranial circulation using moderately flow-redirecting, braided leo stents-initial experience in 39 patients. Front Neurol. (2017) 8:602. doi: 10.3389/fneur.2017.00602

36. Wang CC, Li W, Feng ZZ, Hong B, Xu Y, Liu JM, et al. Preliminary experience with stent-assisted coiling of aneurysms arising from small $(<2.5 \mathrm{~mm})$ cerebral vessels using the low-profile visualized intraluminal support device. AJNR Am J Neuroradiol. (2017) 38:1163-8. doi: 10.3174/ajnr.A5145

37. Cay F, Peker A, Arat A. Stent-assisted coiling of cerebral aneurysms with the Neuroform Atlas stent. Interv Neuroradiol. (2018) 24:2639. doi: $10.1177 / 1591019917753710$

38. Feng X, Qian Z, Liu P, Zhang B, Wang L, Guo E, et al. Comparison of recanalization and in-stent stenosis between the low-profile visualized intraluminal support stent and enterprise stent-assisted coiling for 254 intracranial aneurysms. World Neurosurg. (2018) 109:e99-e104. doi: 10.1016/j.wneu.2017.09.112

39. Gao BL, Li TX, Li L, Xu GQ, Yang BW. Tiny cerebral aneurysms can be treated safely and effectively with low-profile visualized intraluminal support stent-assisted coiling or coiling alone. World Neurosurg. (2018) 113:e42630. doi: 10.1016/j.wneu.2018.02.051

40. Iosif C, Piotin M, Saleme S, Barreau X, Sedat J, Chau Y, et al. Safety and effectiveness of the Low Profile Visualized Intraluminal Support (LVIS and LVIS Jr) devices in the endovascular treatment of intracranial aneurysms: results of the TRAIL multicenter observational study. J Neurointerv Surg. (2018) 10:675-81. doi: 10.1136/neurintsurg-2017-013375

41. Koch MJ, Stapleton CJ, Raymond SB, Williams S, Leslie-Mazwi TM, Rabinov JD, et al. LVIS Blue as a low porosity stent and coil adjuvant. J Neurointerv Surg. (2018) 10:682-6. doi: 10.1136/neurintsurg-2017-013608

42. Peng T, Huang C, Jiang Y, Wan W, Yang X, Liu A, et al. Is Single LowProfile Visualized Intraluminal Support (LVIS)-assisted coiling of widenecked ruptured multiple intracranial aneurysms in one stage feasible? World Neurosurg. (2018) 118:e388-94. doi: 10.1016/j.wneu.2018.06.200

43. Santillan A, Boddu S, Schwarz J, Lin N, Gobin YP, Knopman J, et al. LVIS Jr. stent for treatment of intracranial aneurysms with parent vessel diameter of $2.5 \mathrm{~mm}$ or less. Interv Neuroradiol. (2018) 24:24653. doi: 10.1177/1591019918759307

44. Sedat J, Chau Y, Gaudart J, Sachet M, Beuil S, Lonjon M. Stent-assisted coiling of intracranial aneurysms using LEO stents: long-term follow-up in 153 patients. Neuroradiology. (2018) 60:211-9. doi: 10.1007/s00234-017-1965-1

45. Su W, Zhang Y, Chen J, Liu J, Rajah G, Yang X. 225 intracranial aneurysms treated with the Low-profile Visualized Intraluminal Support (LVIS) stent: a single-center retrospective study. Neurol Res. (2018) 40:44551. doi: 10.1080/01616412.2018.1457608

46. Ulfert C, Pham M, Sonnberger M, Amaya F, Trenkler J, Bendszus M, et al. The Neuroform Atlas stent to assist coil embolization of intracranial aneurysms: a multicentre experience. J Neurointerv Surg. (2018) 10:11926. doi: 10.1136/neurintsurg-2017-013516

47. Wang J, Vargas J, Spiotta A, Chaudry I, Turner RD, Lena J, et al. Stent-assisted coiling of cerebral aneurysms: a single-center clinical and angiographic analysis. J Neurointerv Surg. (2018) 10:687-92. doi: 10.1136/neurintsurg-2017-013272

48. Xu D, Zhang C, Wang T, Wang C, Kallmes DF, Lanzino G, et al. Evaluation of enterprise stent-assisted coiling and telescoping stent technique as treatment of supraclinoid blister aneurysms of the internal carotid artery. World Neurosurg. (2018) 110:e890-6. doi: 10.1016/j.wneu.2017. 11.119

49. Ciccio G, Robert T, Smajda S, Fahed R, Desilles JP, Redjem H, et al. Double stent assisted coiling of intracranial bifurcation aneurysms in $\mathrm{Y}$ and $\mathrm{X}$ configurations with the Neuroform ATLAS stent: immediate and mid term angiographic and clinical follow-up. J Neurointerv Surg. (2019) 11:123942. doi: 10.1136/neurintsurg-2019-015175

50. Djurdjevic T, Young V, Corkill R, Briley D, Küker W. Treatment of broad-based intracranial aneurysms with low profile braided stents: a single center analysis of 101 patients. J Neurointerv Surg. (2019) 11:5917. doi: 10.1136/neurintsurg-2018-014488

51. Goertz L, Dorn F, Siebert E, Herzberg M, Borggrefe J, Schlamann M, et al. Safety and efficacy of the Neuroform Atlas for stent-assisted coiling of intracranial aneurysms: a multicenter experience. J Clin Neurosci. (2019) 68:86-91. doi: 10.1016/j.jocn.2019.07.030 
52. Gross BA, Ares WJ, Ducruet AF, Jadhav AP, Jovin TG, Jankowitz BT. A clinical comparison of Atlas and LVIS Jr stent-assisted aneurysm coiling. $J$ Neurointerv Surg. (2019) 11:171-4. doi: 10.1136/neurintsurg-2018-014208

53. Jankowitz BT, Hanel R, Jadhav AP, Loy DN, Frei D, Siddiqui AH, et al. Neuroform Atlas Stent System for the treatment of intracranial aneurysm: primary results of the Atlas Humanitarian Device Exemption cohort. $J$ Neurointerv Surg. (2019) 11:801-6. doi: 10.1136/neurintsurg-2018-014455

54. Park KY, Jang CK, Lee JW, Kim DJ, Kim BM, Chung J. Preliminary experience of stent-assisted coiling of wide-necked intracranial aneurysms with a single microcatheter. BMC Neurol. (2019) 19:245. doi: 10.1186/s12883-0191470-8

55. Park KY, Kim BM, Kim DJ, Chung J, Lee JW. Y-configuration stenting for coiling of wide-neck bifurcation aneurysms using low-profile visualized intraluminal support junior. J Neurointerv Surg. (2019) 11:400-4. doi: 10.1136/neurintsurg-2018-014128

56. Santillan A, Schwarz J, Boddu S, Gobin YP, Knopman J, Patsalides A. Stent-assisted coil embolization of anterior communicating artery aneurysms using the LVIS Jr stent. Interv Neuroradiol. (2019) 25:1220. doi: $10.1177 / 1591019918798144$

57. Ten Brinck MFM, de Vries J, Bartels R, Grotenhuis JA, Boogaarts HD. NeuroForm atlas stent-assisted coiling: preliminary results. Neurosurgery. (2019) 84:179-89. doi: 10.1093/neuros/nyy048

58. Wu P, Ocak PE, Wang D, Ocak U, Xu S, Li Y, et al. Endovascular treatment of ruptured tiny intracranial aneurysms with lowprofile visualized intraluminal support device. J Stroke Cerebrovasc Dis. (2019) 28:330-7. doi: 10.1016/j.jstrokecerebrovasdis.2018. 09.052

59. Yan Z, Zheng K, Xiong Y, Lan F, Wang Y, Tan X, et al. Intracranial complex ruptured aneurysms coiled with overlapping low-profile visualized intraluminal support stents: another available option for complex ruptured intracranial aneurysms. World Neurosurg. (2019) 125:e22-8. doi: 10.1016/j.wneu.2018.12.142

60. Aydin K, Balci S, Sencer S, Barburoglu M, Umutlu MR, Arat A. Y-Stentassisted coiling with low-profile neuroform atlas stents for endovascular treatment of wide-necked complex intracranial bifurcation aneurysms. Neurosurgery. (2020) 87:744-53. doi: 10.1093/neuros/nyz516

61. Burkhardt JK, Srinivasan V, Srivatsan A, Albuquerque F, Ducruet AF, Hendricks B, et al. Multicenter postmarket analysis of the neuroform atlas stent for stent-assisted coil embolization of intracranial aneurysms. AJNR Am J Neuroradiol. (2020) 41:1037-42. doi: 10.3174/ajnr. A6581

62. Caragliano AA, Papa R, Pitrone A, Limbucci N, Nappini S, Ruggiero M, et al. The low-profile Neuroform Atlas stent in the treatment of wide-necked intracranial aneurysms - immediate and midterm results: an Italian multicenter registry. J Neuroradiol. (2020) 47:421-7. doi: 10.1016/j.neurad.2019.03.005

63. Kim CH, Kim YH, Sung SK, Son DW, Song GS, Lee SW. Clinical safety and effectiveness of stent-assisted coil embolization with neuroform atlas stent in intracranial aneurysm. J Korean Neurosurg Soc. (2020) 63:808. doi: 10.3340/jkns.2019.0154

64. Kwon O, Chung J. Outcomes of stent-assisted coiling using the neuroform atlas stent in unruptured wide-necked intracranial aneurysms. J Korean Neurosurg Soc. (2020) 64:23-9. doi: 10.3340/jkns.2020.0054

65. Oishi H, Fujii T, Yatomi K, Teranishi K, Suzuki K, Mishima Y, et al. Stent-assisted coil embolization of unruptured middle cerebral artery aneurysms using LVIS Jr. stents. J Clin Neurosci. (2020) 80:8791. doi: 10.1016/j.jocn.2020.07.070

66. Poncyljusz W, Zwarzany $Ł$, Limanówka B, Zbroszczyk M, Banach M, Bereza S, et al. Stent-assisted coiling of unruptured MCA aneurysms using the LVIS Jr. Device: a multicenter registry. J Clin Med. (2020) 9:3168. doi: 10.3390/jcm9103168

67. Xue G, Zuo Q, Tang H, Zhang X, Duan G, Feng Z, et al. Comparison of low-profiled visualized intraluminal support stent-assisted coiling and coiling only for acutely ruptured intracranial aneurysms: safety and efficacy based on a propensity score-matched cohort study. Neurosurgery. (2020) 87:58491. doi: 10.1093/neuros/nyaa110

68. Raymond J, Guilbert F, Weill A, Georganos SA, Juravsky L, Lambert A, et al. Long-term angiographic recurrences after selective endovascular treatment of aneurysms with detachable coils. Stroke. (2003) 34:1398403. doi: 10.1161/01.STR.0000073841.88563.E9

69. Cagnazzo F, Cappucci M, Lefevre PH, Dargazanli C, Gascou G, Morganti $\mathrm{R}$, et al. Treatment of intracranial aneurysms with self-expandable braided stents: a systematic review and meta-analysis. AJNR Am J Neuroradiol. (2018) 39:2064-9. doi: 10.3174/ajnr.A5804

Conflict of Interest: The authors declare that the research was conducted in the absence of any commercial or financial relationships that could be construed as a potential conflict of interest.

Copyright (C) 2021 Zhang, Chen, Dong, Liu, Jia, Zhang and Lv. This is an open-access article distributed under the terms of the Creative Commons Attribution License (CC $B Y)$. The use, distribution or reproduction in other forums is permitted, provided the original author(s) and the copyright owner(s) are credited and that the original publication in this journal is cited, in accordance with accepted academic practice. No use, distribution or reproduction is permitted which does not comply with these terms. 